\title{
BMJ Open Interrupted time-series analysis of the impact of generic market entry of antineoplastic products in China
}

\author{
Xiaodong Guan, ${ }^{1,2}$ Ye Tian, ${ }^{1}$ Dennis Ross-Degnan, ${ }^{3}$ Chunxia Man, ${ }^{1}$ Luwen Shi ${ }^{1,2}$
}

To cite: Guan X, Tian Y, RossDegnan $\mathrm{D}$, et al. Interrupted time-series analysis of the impact of generic market entry of antineoplastic products in China. BMJ Open 2018;8:e022328. doi:10.1136/ bmjopen-2018-022328

- Prepublication history and additional material for this paper are available online. To view these files, please visit the journal online (http://dx.doi. org/10.1136/bmjopen-2018022328).

Received 13 February 2018 Revised 5 June 2018 Accepted 18 June 2018

Check for updates

(c) Author(s) (or their employer(s)) 2018. Re-use permitted under CC BY-NC. No commercial re-use. See rights and permissions. Published by BMJ.

${ }^{1}$ Department of Pharmacy Administration and Clinical Pharmacy, School of Pharmaceutical Sciences, Peking University, Beijing, China ${ }^{2}$ International Research Center for Medicinal Administration, Peking University, Beijing, China ${ }^{3}$ Department of Population Medicine, Harvard Medical School and Harvard Pilgrim Health Care Institute, Boston, Massachusetts, USA

Correspondence to

Professor Luwen Shi; shiluwen211@163.com

\section{ABSTRACT}

Objectives The rapid growth of pharmaceutical costs is a major healthcare issue all over the world. The high prices of new drugs, especially those for cancer, are also a concern for stakeholders. Generic drugs are a major pricereducing opportunity and provide more societal value. The aim of this research is to analyse the impact of generic entry on the volume and cost of antineoplastic agents in China.

Methods An interrupted time-series design examined monthly sales of three antineoplastic drugs (capecitabine, decitabine, imatinib) from 699 public hospitals during January 2011 to June 2016. The first generic entry times (December 2013, December 2012, August 2013, respectively) were regarded as the intervention time points. We estimated changes in volume and cost following the generic entry.

Results We found that generic entry was associated with increases in the volume of three antineoplastic agents and decreases in their costs. In terms of volume, generic entry was associated with increases in use of capecitabine, decitabine and imatinib by $815.0(95 \% \mathrm{Cl}-66.5$ to 1696.5, $\mathrm{p}>0.05), 11.0(95 \% \mathrm{Cl} 3.7$ to $18.3, \mathrm{p}=0.004)$ and $2145.5(95 \% \mathrm{Cl} 1784.1$ to $2506.9, \mathrm{p}<0.001)$ units. The entry of generic antineoplastic drugs reduced the monthly cost trend of three agents by $¥ 3.1(95 \% \mathrm{Cl}-¥ 3.6$ to $-¥ 2.6, p<0.001), ¥ 84.7(95 \% \mathrm{Cl}-¥ 104.7$ to $-¥ 64.6$, $p<0.001)$ and $¥ 21.3(95 \% \mathrm{Cl}-¥ 24.2$ to $-¥ 18.4, p<0.001)$, respectively. The entry of generic drugs attenuated the upward trend in volume of three brand-name drugs and even triggered reductions in the volume of brand-name capecitabine. The entry of generics was accompanied by significant increase of $¥ 2.6$ in monthly brand-name decitabine cost $(95 \% \mathrm{Cl} ¥ 0.2$ to $¥ 5.1, p=0.04$ ).

Conclusion Our findings suggested that entry of generic drugs impacted use and cost of antineoplastic medicines in China. Generic drugs may improve the availability and the affordability of antineoplastic agents, which would benefit more patients.

\section{INTRODUCTION}

The rising cost of healthcare is an issue for consumers and stakeholders alike in almost every country. Patent protection entitles brand-name drug exclusivity in the market, permitting patent holders to maintain high prices to maximise profit. ${ }^{1}$ The entry of less expensive generic products and the

\section{Strengths and limitations of this study}

This study used complete drug procurement records from 699 hospitals in the China Medicine Economic Information Database to present the first analysis of the impact of generic entry in the antineoplastic market in China.

- We used interrupted time-series analysis to evaluate trends before and after generic market entry, a well-established method to analyse changes in drug utilisation and cost after an intervention at a defined point in time.

- This study only gave an overview of drug utilisation trend over time without assessing drug utilisation by individual patient.

- We only found three antineoplastic agents with first generic entry in the observation period, which may not represent the whole market.

subsequent availability of a greater selection of substitutes for consumers may trigger lower prices for brand-name products. ${ }^{2}$ Additionally, the entry of generic medicines might also lead to more optimal treatment of some diseases with additional patients benefitting from access to the medicines. ${ }^{3}$

High-quality generic drugs offer a major opportunity for economic efficiency due to their lower prices and similar quality. ${ }^{45}$ Many countries adopt policies to increase the use of generic medicines. ${ }^{6-8}$ Some studies found that after generic entry, more patients are switched to the generic substitutes, ${ }^{9} 10$ while others showed that the brand-name products are still used more than the generic alternatives. ${ }^{11}$ The literature has shown mixed evidence about the impact of generic entry on brand-name price. Some research has indicated that brand-name prices tended to fall following the entry of generic alternatives ${ }^{12-14}$ while others have found that brandname manufacturers continue to increase their prices at the same rate as prior to the introduction of generics. ${ }^{15-17}$ This contradiction is known as the generic competition paradox. ${ }^{18}$ Evidence related to changes in 
the overall therapeutic market is limited. Some analyses have found that the average cost per user for medicines decreased after generic entry. ${ }^{19}{ }^{20}$ Evidence related to changes in utilisation following the entry of generic medicines has highlighted the contribution of generics to increased availability of medicines in overall therapeutic market. ${ }^{21} 22$

China still faces challenges in transforming from a profit-oriented public hospital-centred system to an integrated primary care-based delivery system. ${ }^{23}$ Healthcare facilities customarily obtain medicines from eligible suppliers through a centralised province-wide supply system at agreed prices negotiated by the provincial government and suppliers. ${ }^{24} \mathrm{~A}$ zero-markup policy was introduced which prevents hospitals from marking up essential medicines in order to remove perverse economic incentives for overprescription. ${ }^{25}$ Nevertheless physicians are still incentivised to make a profit from medicines. ${ }^{26}$

High pharmaceutical prices have attracted a great deal of attention from the public and the government in China. Medicine prices, particularly for brand-name drugs, remain significantly higher than the international reference prices. ${ }^{27}{ }^{28}$ Patent protection for originator products and perceptions about lower safety and efficacy of generics have contributed to the prices of patent originals (and even off-patent originals) remaining higher than those of generic alternative. ${ }^{29-31} \mathrm{Hu}$ et al illustrated a consistent average price difference of approximately $40 \%$ between off-patent brand-names and generics in the 10-year period from 2002 to $2011 .{ }^{29}$ Using data from Shaanxi province, Jiang et al showed that in private sector retail pharmacies, the median price for original brands was 5.5 times the price of the lowest price generic equivalents, while in public sector health facilities, the ratio can be 11.3 or more. ${ }^{27}$

There has been little empirical evidence about the impact of generic market entry in China. ${ }^{30} 31$ Thus, the objective of this study is to analyse the effect of the market entry of generic alternatives for three antineoplastic medications on utilisation and cost in order to provide evidence about how the market responds in terms of price and utilisation.

\section{METHODS}

\section{Data source}

Data were derived from China Medicine Economic Information, a large database covering procurement records of 1117 hospitals in 2016 in mainland China. We conducted a search of 115 antineoplastic agents (all antineoplastic agents in the database) from January 2011 to June 2016, and only found three antineoplastic agents (capecitabine, decitabine and imatinib) that experienced first entry of a generic substitute in the study period. A total of 699 tertiary hospitals had complete procurement records in this period and these were included in our study. Records included the purchasing volume and cost of individual drugs, and basic information on the date of purchasing, the Anatomical Therapeutic Chemical code of the product, as well as the manufacturer; 66 monthly values of expenditure and consumption for each of the three antineoplastic agents comprised our samples. Online supplementary table 1 provides the descriptive information for these three drugs.

\section{Outcome measures}

This study assessed the effect of generic entry on both volume and procurement cost of medicine in this study (total medication and brand-name drug for each antineoplastic agent). The daily dose (DD) in this paper was the daily amounts based on dosage regimen recommended in the manufacturers' instructions of the three products, as approved by China Food and Drug Administration (CFDA). The maintenance dose of capecitabine, decitabine and imatinib in this study were $1250 \mathrm{mg}, 15 \mathrm{mg}$ and $500 \mathrm{mg}$, respectively. We used maintenance dose to calculate numbers of DD (a standardised measure of the volume of each product procured) and cost per DD (a standardised measure of the procurement cost of each product), respectively.

\section{Statistical analysis}

We first created graphical displays of the monthly procurement volume and cost of each study medication in order to observe and describe patterns over time. We then summed the monthly volumes and procurement costs of each medication to determine total monthly volume and total cost; we calculated the average monthly cost as the total monthly volume divided by the total monthly cost. The expense data were reported in both Chinese yuan and US\$ (¥1=US\$0.155 based on the 2011 exchange rate). ${ }^{32}$

We used interrupted time-series (ITS) analysis of each study medication to assess the change in total volume and average cost associated with generic entry of substitute products. ITS is a commonly used approach for evaluating changes in longitudinal series following a quasi-experimental intervention occurring at a fixed point in time, such as the date of market entry of generic alternatives. The date of first generic product entering the market (December 2013, December 2012 and August 2013 for capecitabine, decitabine and imatinib, respectively, see online supplementary table 1 ) was regarded as the intervention time point for ITS analyses. We used segmented regression models that control for baseline trends to estimate changes in the levels and trends of total volume and average cost after generic market entry.

The following model was used for the analysis:

$$
Y_{t}=\beta_{0}+\beta_{1} * \text { time }_{t}+\beta_{2} * \text { entry }_{t}+\beta_{3} * \text { timeafterentry }_{t}+\varepsilon_{t}
$$

$Y_{t}$ is the independent outcome variable (total volume or average cost). $\beta_{0}$ estimates the level of the outcome at the beginning of the observation period. $\beta_{1}$ estimates the linear trend during the preintervention period where time $_{t}$ is an integer variable indicating the time in months at time $t$ from the beginning of the study period. $\beta_{2}$ which 
is coded as $t i m e_{t}=0$ is before generic entry and time $e_{t}=1$ is after the entry estimates the change in the outcome immediately following the market entry. $\beta_{3}$ estimates the change in trend in the outcome in the postentry period compared with baseline. $\varepsilon_{t}$ is an estimate of the random error at time $t$. We set the time point immediately following first market entry to missing in these models in order to allow time for market adjustment and used the DurbinWatson statistic to test for a serial autocorrelation of the error terms in the regression models. We performed the ITS analysis using STATA V.13.0.

\section{Patient and public statement}

Patients or public were not involved in this study.

\section{RESULTS}

\section{Descriptive analysis of changes in volume and cost}

The monthly sales of the all three antineoplastic agents increased over time following market entry of generics, although increases in the volume of the brand-name medications tended to attenuate (online supplementary figure $1 \mathrm{~A}-\mathrm{C})$. For capecitabine, the brand medication remained the dominant product throughout the study period exceeding the total volume of all generic substitutes; for decitabine and imatinib, one of the generic alternatives increased to approximately the same volume as the brand medicine, and total volume of generic alternatives exceeded the brand product.

The cost of all three brand-name antineoplastic drugs remained nearly constant or experienced only a small decrease following market entry of generics, while the cost of most generic drugs decreased over time (online supplementary figure $1 \mathrm{D}-\mathrm{F}$ ). The cost of all generic drugs was consistently lower than the cost of brand-name drugs. By the end of the observation period, the cost of all generic capecitabine was roughly half of the brand product, while all generic imatinib were only $10 \%-20 \%$ of the brand. The cost of generic decitabine, though with high cost variance, was $40 \%-60 \%$ of the brand product by the end of the observation period.

\section{ITS analysis of changes in total volume and average treatment cost}

The entry of generic drugs triggered increases in the total volume of decitabine and imatinib, as well as reductions in the average cost of treatment for the three drugs (figure 1, table 1). Capecitabine volume was increasing by 1752.5 DDs per month prior to generic entry. There was no significant change in either level or trend of capecitabine volume observed following the launch of the generic versions of the drug. For decitabine, prior to generic entry, the overall volume was increasing by $8.8 \mathrm{DDs}$ per month. There was a significant increase of $11.0 \mathrm{DDs}$ (95\% CI 3.7 to $18.3, \mathrm{p}=0.004$ ) per month in overall volume after generic entry. The volume was 437.7 DDs (95\% CI 193.6 to 681.7), higher than expected at the end of observation period. Similarly, the entry of a generic substitute was associated with the acceleration in the upward pregeneric increase of 817.8 DDs of imatinib. Following generic entry, the total volume of imatinib increased by an additional 2145.5 DDs per month (95\% CI 1784.1 to 2506.9, $\mathrm{p}<0.001$ ), resulting in an estimated increase of 82559.3 DDs in the last month of the observation period (95\% CI 61461.9 to 103656.9 ). There was no significant change in either the level or the trend of capecitabine volume following the launch of its generic alternative. The trend in average cost of all three agents was stable prior to generic entry with the downward trend of capecitabine (-¥1.0 per month, 95\% CI - ¥1.3 to -¥0.7), decitabine (-¥3.3 per month, 95\% CI $¥ ¥ 22.0$ to $¥ 15.3$ ) and imatinib (-¥0.1 per month, 95\% CI $¥ 2.3$ to $¥ 2.1$ ). The entry of generics was accompanied by significant monthly reductions in the cost of capecitabine, decitabine and imatinib of $¥ 3.1$ (US $\$ 0.5 ; 95 \%$ CI $-¥ 3.6$ to $-¥ 2.6, \mathrm{p}<0.001$ ), ¥84.7 (US\$13.1; 95\% CI - ¥104.7 to - ¥64.6, p<0.001) and ¥21.3 (US\$3.3; 95\% CI - ¥24.2 to - ¥18.4, p<0.001) per month, respectively. By the end of the study period, this led to estimated reductions in average daily treatment cost of the three antineoplastic medications of $¥ 130.3$ (US\$20.2; $95 \%$ CI $¥ ¥ 142.6$ to $¥ ¥ 118.0$ ), $¥ 3266.4$ (US $\$ 506.3 ; 95 \%$ CI

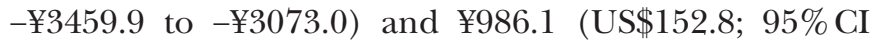
-¥1055.8 to - ¥916.3), respectively.

\section{ITS analysis of changes in volume and average treatment cost} for brand-name drugs

The entry of generic drugs attenuated the upward trend in the volume of three brand-name drugs and even triggered reductions in the volume of brand-name capecitabine. Meanwhile, there were no significant changes of average treatment cost of the brand-name capecitabine and imatinib, while the downward trend of brand-name decitabine cost was attenuated following the generic entry (figure 2, table 2). Before generic entry, the volume of brand-name capecitabine, decitabine and imatinib experienced increasing trend by 1752.5, 8.5 and 815.1 DDs per month. Generic entry led to an immediate increase of 8278.3 DDs in brand-name imatinib volume (95\% CI 2396.6 to $14160.1, \mathrm{p}=0.007$ ). There was a significant decreasing trend in the volume of brand-name capecitabine, decitabine and imatinib, respectively (95\% CI -3206.8 to $-1644.8, \mathrm{p}<0.001 ; 95 \%$ CI -13.1 to $-3.4, \mathrm{p}<0.001 ; 95 \% \mathrm{CI}-1022.7$ to $-391.2, \mathrm{p}<0.001)$ after the entry of generic drugs. This resulted in an estimated decrease of 99 342.2 DDs, 283.8 DDs and 22 227.6 DDs in the volume of brand-name capecitabine, decitabine and imatinib in the last month of the observation period (95\% CI -133858.0 to $-64826.9, \mathrm{p}<0.001 ; 95 \%$ CI -497.3 to $-70.2, \mathrm{p}=0.009 ; 95 \% \mathrm{CI}-37807.7$ to $-6647.4, \mathrm{p}=0.005)$. The downward trend in cost of brand-name capecitabine and decitabine was stable $(95 \% \mathrm{CI}-1.4$ to $-0.6, \mathrm{p}<0.001$; $95 \% \mathrm{CI}-5.4$ to $-0.8, \mathrm{p}=0.008$ ) while the decreasing trend of brand-name imatinib was not significant. The entry of generics was accompanied by significant increase in the cost of brand-name decitabine of $¥ 2.6$ (US $\$ 0.4$; 95\% CI $¥ 0.2$ to $¥ 5.1, \mathrm{p}=0.04$ ) per month. By the end of the study 

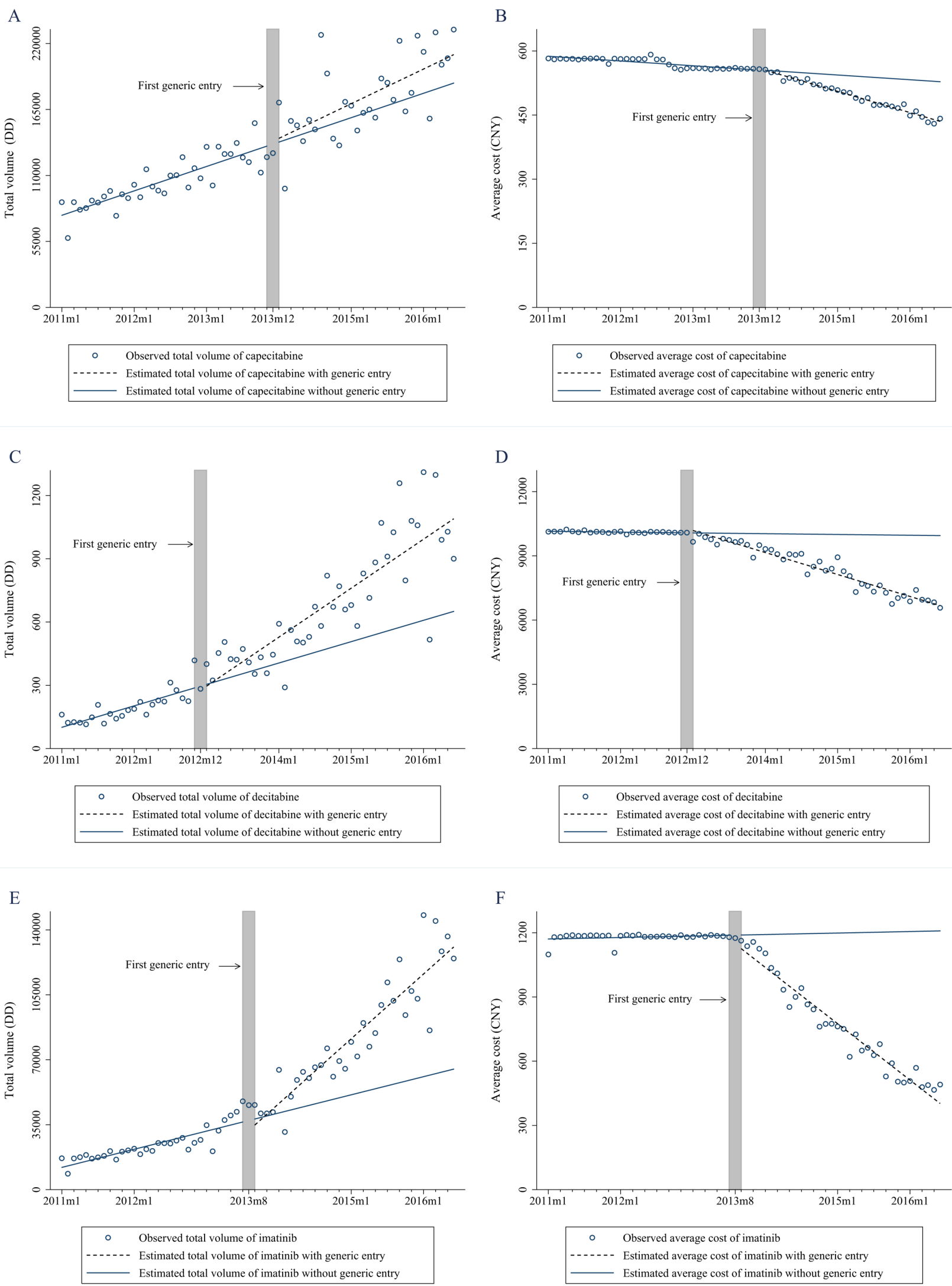

Figure 1 Change in total volume and daily cost for three antineoplastic agents before and after generic entry. (A) Total volume of all products of capecitabine; (B) average cost of all products of capecitabine; (C) total volume of all products of decitabine; (D) average cost of all products of decitabine; (E) total volume of all products of imatinib; $(F)$ average cost of all products of imatinib. CNY, Chinese yuan; DD, daily dose. 
Table 1 Estimates from interrupted time-series models of changes in total volume and average treatment cost for all versions of three antineoplastic medications following generic market entry (baseline trend, postentry level and trend changes, and absolute changes at the end of observation period)

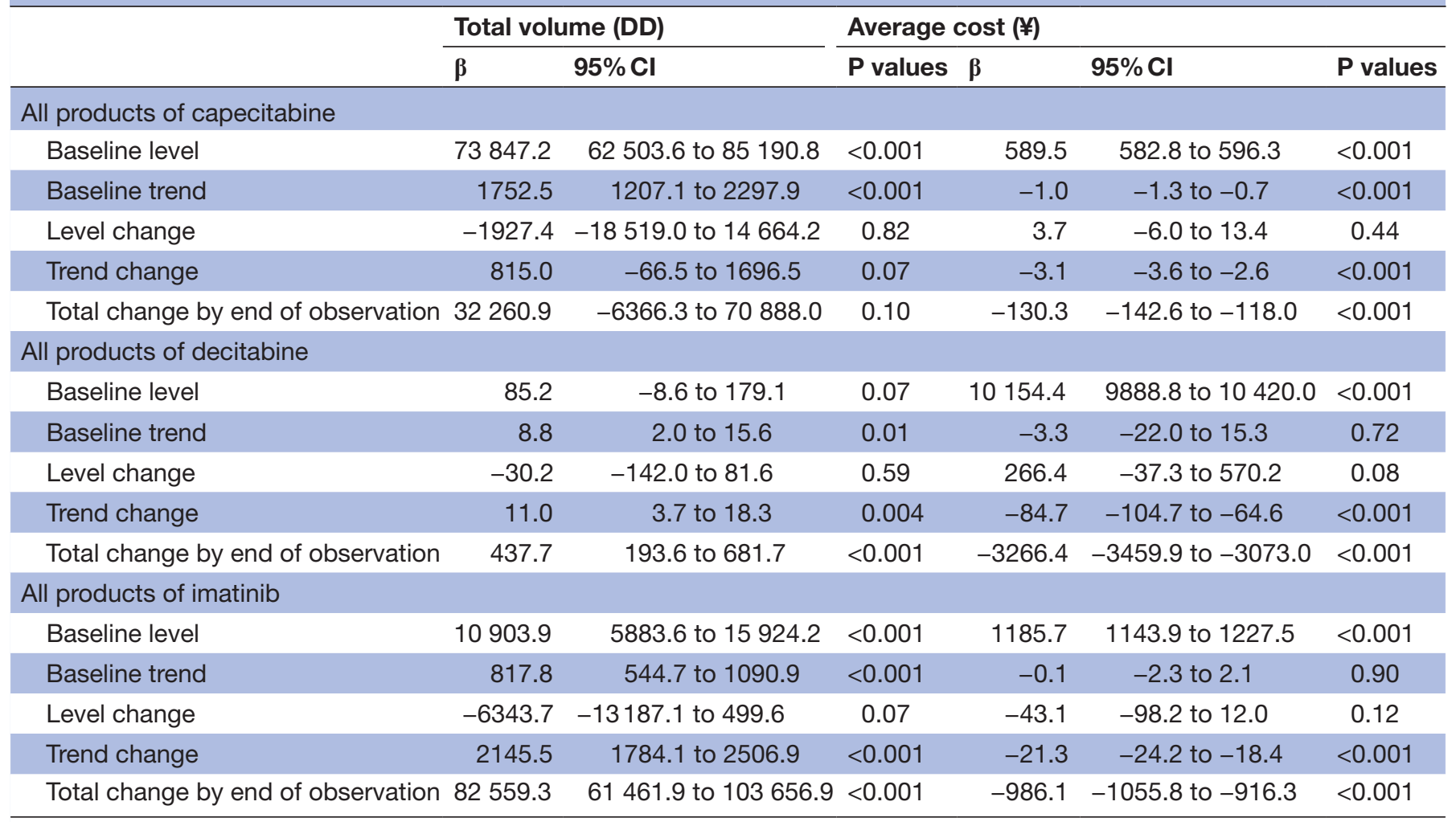

$\mathrm{DD}$, daily dose.

period, generic entry led to the estimated increase in average daily treatment cost of brand-name capecitabine and decitabine of $¥ 28.8$ (US\$4.5; $95 \%$ CI $¥ 19.9$ to $¥ 37.6$, $\mathrm{p}<0.001$ ) and $¥ 124.6$ (US $\$ 19.3 ; 95 \%$ CI $¥ 9.5$ to $¥ 239.8$, $\mathrm{p}=0.03$ ), respectively, while led to the estimated reduction in the cost of imatinib of $¥ 109.7$ (US\$17.0; $95 \%$ CI - $¥ 168.0$ to $¥ ¥ 51.4, \mathrm{p}<0.001)$.

\section{DISCUSSION}

Our study showed that generic entry was associated with increases in the total volume of antineoplastic agents for each of the three study medications, with decreases in volume of the brand-name product. Rather than simply replacing the reductions of brand utilisation with lower priced generics, generic entry resulted in increases in the overall market volume. The increased overall use of the three antineoplastic agents suggested that generic entry had a positive effect on the availability, financial accessibility and overall utilisation of the agents. The growing number of users for these important medications showed that generic entry improved patient access for those who may have been unable to afford the more expensive brand-name drugs. ${ }^{3} 33$

Because generic prices tended to be much lower than the prices of brand-name drugs, the average cost per treatment declined substantially after generic entry. This confirmed that generic entry can increase the affordability of pharmaceuticals for patients. The entry of generic drugs resulted in considerable savings and more efficient resource allocation for the Chinese healthcare system, consistent with previous studies. ${ }^{34} 35$

Consistent with previous research, generic entry also had impact on use of brand-name drugs in our study. ${ }^{19} 20$ The increasing volume of brand-name decitabine and imatinib experienced attenuation following the entry of generic alternatives, while the volume of brand-name capecitabine began to decrease. The latter may have been because capecitabine was the only drug of the three listed in national reimbursement drug list since 2009. Under the pressure of increasing deficits in China's medical insurance system, ${ }^{23}$ physicians are forced to prescribe generic drugs. This might explain why uptake of generic capecitabine differs from the other two drugs studied. Current studies have demonstrated that insurance coverage enhances medicine adherence and access. ${ }^{35} 36$ Although China has reached near-universal coverage after health reform since 2009, ${ }^{37}$ only 20 targeted antineoplastic agents were approved by CFDA before 2017 and none was listed in the national reimbursement drug list. ${ }^{38} 39$ Thus, a strategy to reduce the out-of-pocket cost for these highcost medicines in China is urgently needed.

We also found that daily treatment cost of the three brand-name drugs tended to remain stable after the entry of generic alternatives, or to decrease only slightly. This 

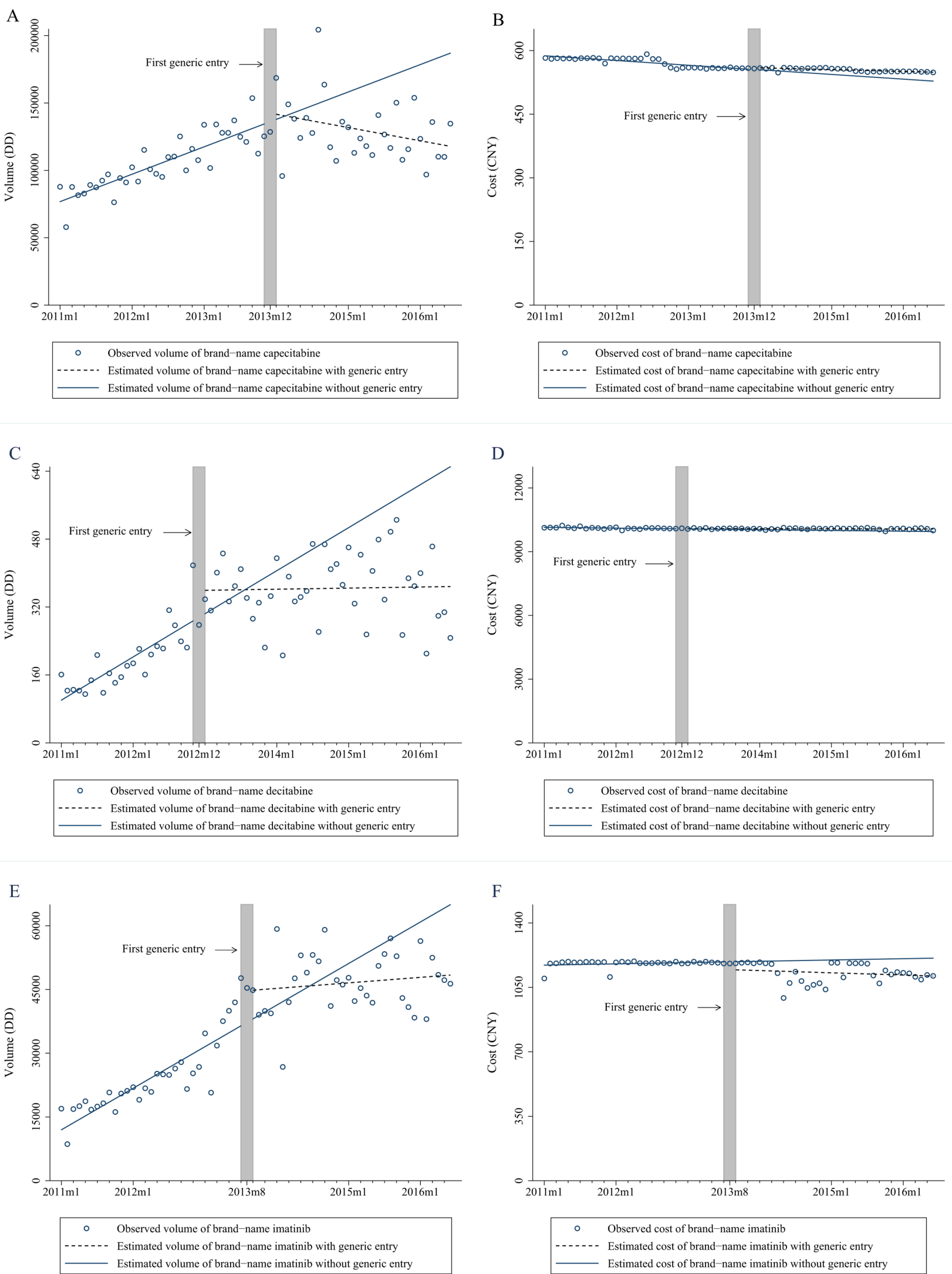

Figure 2 Change in volume and daily cost for three brand-name drugs before and after generic entry. (A) Volume of brandname capecitabine; (B) average cost of brand-name capecitabine; (C) total volume of brand-name decitabine; (D) average cost of brand-name decitabine; (E) total volume of brand-name imatinib; $(\mathrm{F})$ average cost of brand-name imatinib. CYN, Chinese yuan; DD, daily dose. 
Table 2 Estimates from interrupted time-series models of changes in volume and cost for three brand-name antineoplastic medications following generic market entry (baseline trend, postentry level and trend changes, and absolute changes at the end of observation period)

\begin{tabular}{|c|c|c|c|c|c|c|}
\hline & \multicolumn{3}{|c|}{ Volume (DD) } & \multicolumn{3}{|l|}{ Cost (\#) } \\
\hline & $\boldsymbol{\beta}$ & $95 \% \mathrm{Cl}$ & P values & $\boldsymbol{\beta}$ & $95 \% \mathrm{Cl}$ & $P$ values \\
\hline \multicolumn{7}{|l|}{ Brand-name capecitabine } \\
\hline Baseline trend & 1752.5 & 1269.2 to 2235.7 & $<0.001$ & -1.0 & -1.4 to -0.6 & $<0.001$ \\
\hline Level change & 2333.7 & -12366.5 to 17034.0 & 0.75 & 5.4 & -6.6 to 17.4 & 0.37 \\
\hline $\begin{array}{l}\text { Total change by end of } \\
\text { observation }\end{array}$ & -99342.2 & -133858.0 to -64826.9 & $<0.001$ & 28.8 & 19.9 to 37.6 & $<0.001$ \\
\hline \multicolumn{7}{|l|}{ Brand-name decitabine } \\
\hline Baseline level & 92.2 & 31.0 to 153.5 & 0.004 & 10150.7 & 10119.4 to 10182.0 & $<0.001$ \\
\hline Baseline trend & 8.5 & 4.0 to 12.9 & $<0.001$ & -3.1 & -5.4 to -0.8 & 0.008 \\
\hline \multicolumn{7}{|l|}{ Brand-name imatinib } \\
\hline Baseline level & 11171.1 & 6806.0 to 15536.3 & $<0.001$ & 1190.6 & 1139.6 to 1241.6 & $<0.001$ \\
\hline Baseline trend & 815.1 & 577.0 to 1053.3 & $<0.001$ & -0.4 & -3.0 to 2.3 & 0.79 \\
\hline Level change & 8278.3 & 2396.6 to 14160.1 & 0.007 & -41.7 & -107.6 to 24.2 & 0.21 \\
\hline Trend change & -706.9 & -1022.7 to -391.2 & $<0.001$ & -0.3 & -3.8 to 3.2 & 0.87 \\
\hline $\begin{array}{l}\text { Total change by end of } \\
\text { observation }\end{array}$ & -22227.6 & -37807.7 to -6647.4 & 0.005 & -109.7 & -168.0 to -51.4 & $<0.001$ \\
\hline
\end{tabular}

DD, daily dose.

illustrates that brand-name manufacturers did not tend to decrease the prices of their products when facing generic competition. Segmentation of the market might explain this phenomenon. ${ }^{34}$ 'Loyal consumers' continuing to use these products-in this case oncologists who prefer them-allowed brand-name manufacturers to maintain their high price levels with relatively stable volumes. Information asymmetry may be a contributing cause for this phenomenon; some oncologists may have been more familiar with the brand product than the newer generic substitutes, or they may have been motivated by economic incentives. Furthermore, physicians may have felt a responsibility to ensure that patients received the best therapy. Local generics are not required to be bioequivalent and may be of lower quality, so doctors prefer brand-name products in clinical use. ${ }^{2640}$ Moreover, incentivised by a $15 \%$ mark-up rule, hospitals might seek to evade price ceilings by switching to more expensive drugs during the study period. ${ }^{41}$ Patients' preferences for brand-name drugs could also constitute a barrier to generic substitution, although this may be a less likely explanation for antineoplastic medications. ${ }^{42}$

However, the results of this study should be interpreted in light of several limitations. First, we were unable to assess drug utilisation by individual patients, since only aggregate consumption data were available. Drug consumption data presented in DD only provide an estimate of the volume of medications consumed and do not present a precise picture of actual use. Second, we found only three antineoplastic drugs that had a generic enter the market in the observation period, and these three examples may not represent all antineoplastic medications. In addition, we only focused on the antineoplastic market, so our conclusions may not generalise to other product classes, especially those that do not share the unique features of oncology treatment. Finally, we were unable to measure institutional factors that may have affected prescribing patterns and prices in the Chinese health system during the observation period.

\section{CONCLUSIONS}

This study demonstrated that the generic entry had substantial positive impacts on the antineoplastic market in China. Generic entry improved the availability of antineoplastic therapy, increased affordability and generated cost savings through reduced average treatment costs, which will benefit more patients. However, this study also showed that generic entry had a negative impact on brand-name drugs sales, 
although the expected reduction in brand-name prices due to competition did not occur.

Acknowledgements We acknowledge all the participants in the study. We are also grateful for the support and cooperation of the staff from the Scientific Development Center of China Pharmacy Association.

Contributors XG, DR-D and LS conceptualised and designed the study. YT screened and completed data extractions. YT and CM contributed to analysis of the data. XG, DR-D and YT conducted the final analysis and drafted the initial manuscript. All authors contributed to the critical revision of the paper and approved the final manuscript.

Funding This research received no specific grant from any funding agency in the public, commercial or not-for-profit sectors.

Competing interests None declared.

Patient consent Not required.

Ethics approval Ethical approval was not required according to the relevant requirements for conducting this type of survey in China.

Provenance and peer review Not commissioned; externally peer reviewed.

Data sharing statement № additional data are available.

Open access This is an open access article distributed in accordance with the Creative Commons Attribution Non Commercial (CC BY-NC 4.0) license, which permits others to distribute, remix, adapt, build upon this work non-commercially, and license their derivative works on different terms, provided the original work is properly cited, appropriate credit is given, any changes made indicated, and the use is non-commercial. See: http://creativecommons.org/licenses/by-nc/4.0/.

\section{REFERENCES}

1. Hill A, Gotham D, Fortunak J, et al. Target prices for mass production of tyrosine kinase inhibitors for global cancer treatment. BMJ Open 2016;6:e9586.

2. Dylst $P$, Simoens $S$. Does the market share of generic medicines influence the price level?: a European analysis. Pharmacoeconomics 2011;29:875-82.

3. Dylst P, Vulto A, Simoens S. Societal value of generic medicines beyond cost-saving through reduced prices. Expert Rev Pharmacoecon Outcomes Res 2015;15:701-11.

4. Corrao G, Soranna D, Merlino L, et al. Similarity between generic and brand-name antihypertensive drugs for primary prevention of cardiovascular disease: evidence from a large population-based study. Eur J Clin Invest 2014;44:933-9.

5. Kesselheim AS, Misono AS, Lee JL, et al. Clinical equivalence of generic and brand-name drugs used in cardiovascular disease: a systematic review and meta-analysis. JAMA 2008;300:2514-26.

6. King DR, Kanavos P. Encouraging the use of generic medicines: implications for transition economies. Croat Med J 2002;43:462-9.

7. Dylst P, Vulto A, Godman B, et al. Generic medicines: solutions for a sustainable drug market? Appl Health Econ Health Policy 2013;11:437-43.

8. Kanavos P. Measuring performance in off-patent drug markets: a methodological framework and empirical evidence from twelve EU Member States. Health Policy 2014;118:229-41.

9. Grabowski H, Long G, Mortimer R. Recent trends in brand-name and generic drug competition. J Med Econ 2014;17:207-14.

10. Fukumoto D, Suzuki T. Impact of generic entry to off-patent branded medicines in Japanese pharmaceutical market. Journal of Generic Medicines: The Business Journal for the Generic Medicines Sector 2017;13:114-22

11. Labiris G, Fanariotis M, Kastanioti C, et al. Greek physicians' perceptions on generic drugs in the era of austerity. Scientifica 2015;2015:251792-9.

12. Wiggins SN, Maness R. Price Competition in Pharmaceuticals: The Case of Anti-infectives. Econ Inq 2004;42:247-63.

13. Pavenik N. Do pharmaceutical prices respond to potential patient out-of-pocket expenses? Rand J Econ 2002;33:469-87.

14. Lee JSF, Sagaon Teyssier L, Dongmo Nguimfack B, et al. An analysis of volumes, prices and pricing trends of the pediatric antiretroviral market in developing countries from 2004 to 2012. BMC Pediatr 2016;16:41-9.

15. Grabowski H, Vernon J. Longer patents for increased generic competition in the US. The Waxman-Hatch Act after one decade. Pharmacoeconomics 1996;10(Suppl 2):110-23.
16. Vandoros $S$, Kanavos $P$. The generics paradox revisited: empirical evidence from regulated markets. Appl Econ 2013;45:3230-9.

17. Lexchin J. The effect of generic competition on the price of brandname drugs. Health Policy 2004;68:47-54.

18. Scherer FM. Pricing, profits, and technological progress in the pharmaceutical industry. J Econ Perspect 1993;7:97-115.

19. Boersma C, Klok RM, Bos JM, et al. Drug costs developments after patent expiry of enalapril, fluoxetine and ranitidine. Appl Health Econ Health Policy 2005;4:191-6.

20. Kaojarern S, Pattanaprateep O. The effect of introducing inpatient mandatory generic drug substitution at Ramathobodi Hospital. J Med Assoc Thai 2012;95:519-25.

21. Godman B, Persson M, Miranda J, et al. Changes in the utilization of venlafaxine after the introduction of generics in Sweden. Appl Health Econ Health Policy 2013;11:383-93.

22. Bazargani YT, Ewen M, de Boer A, et al. Essential medicines are more available than other medicines around the globe. PLoS One 2014;9:e87576.

23. Yip W, Hsiao W. Harnessing the privatisation of China's fragmented health-care delivery. Lancet 2014;384:805-18.

24. Yang L, Huang C, Liu C. Distribution of essential medicines to primary care institutions in Hubei of China: effects of centralized procurement arrangements. BMC Health Serv Res 2017;17:727.

25. Wei X, Yin J, Walley JD, et al. Impact of China's essential medicines scheme and zero-mark-up policy on antibiotic prescriptions in county hospitals: a mixed methods study. Trop Med Int Health 2017;22:1166-74.

26. Chen C, Dong W, Shen JJ, et al. Is the prescribing behavior of Chinese physicians driven by financial incentives? Soc Sci Med 2014;120:40-8.

27. Jiang M, Zhou Z, Wu L, et al. Medicine prices, availability, and affordability in the Shaanxi Province in China: implications for the future. Int J Clin Pharm 2015;37:12-17.

28. Chen J, Nie X, Yao P, et al. TRIPS-plus and access to medicines in China. J Public Health Policy 2013;34:226-38.

29. Hu S, Zhang Y, He J, et al. A case study of pharmaceutical pricing in China: setting the price for off-patent originators. Appl Health Econ Health Policy 2015;13(Suppl1):13-20.

30. Wang YR. Price competition in the Chinese pharmaceutical market. Int J Health Care Finance Econ 2006;6:119-29.

31. Liu YM, Yang YH, Hsieh CR. Regulation and competition in the Taiwanese pharmaceutical market under national health insurance. $J$ Health Econ 2012;31:471-83.

32. Guo LW, Huang HY, Shi JF, et al. Medical expenditure for esophagea cancer in China: a 10-year multicenter retrospective survey (20022011). Chin J Cancer 2017;36:73.

33. Cameron A, Mantel-Teeuwisse AK, Leufkens HG, et al. Switching from originator brand medicines to generic equivalents in selected developing countries: how much could be saved? Value Health 2012;15:664-73.

34. Regan TL. Generic entry, price competition, and market segmentation in the prescription drug market. Int J Ind Organ 2008;26:930-48.

35. Simoens S, Sinnaeve PR. Patient co-payment and adherence to statins: a review and case studies. Cardiovasc Drugs Ther 2014;28:99-109.

36. Qiu Q, Duan XW, Li Y, et al. Impact of partial reimbursement on hepatitis B antiviral utilization and adherence. World J Gastroenterol 2015;21:9588-97.

37. Li Y, Malik V, Hu FB. Health Insurance In China: after declining in the 1990s, coverage rates rebounded to near-universal levels by 2011. Health Aff 2017;36:1452-60.

38. China Food and Drug Administration. Database of approved active pharmaceutical ingredients (APIs) and API manufacturers in China. http://app1.sfda.gov.cn/datasearcheng/face3/base. jsp?tableld=85\&tableName=TABLE85\&title=Database $\% 20$ of $\%$ 20approved\%20Active\%20Pharmaceutical\%20Ingredients\% 20(APIs)\%20and\%20API\%20manufacturers \%20in\%20 China\&bcld=136489131226659132460942000667 (accessed 17 Apr 2018).

39. Ministry of Human Resources and Social Security of the People's Republic of China. National reimbursement drug list. 2009 http:// www.mohrss.gov.cn/SYrlzyhshbzb/fwyd/zaixianchaxun/xxcx/ sygjjbbxml/yaopinminglu2009/mulu/ (accessed 17 Apr 2018).

40. Huang B, Barber SL, Xu M, et al. Make up a missed lesson-New policy to ensure the interchangeability of generic drugs in China. Pharmacol Res Perspect 2017;5:e00318.

41. Han S, Liang H, Su W, et al. Can price controls reduce pharmaceutical expenses? A case study of antibacterial expenditures in 12 Chinese hospitals from 1996 to 2005. Int J Health Serv 2013;43:91-103.

42. Shrank WH, Cox ER, Fischer MA, et al. Patients' perceptions of generic medications. Health Aff 2009;28:546-56. 